УДК 159.923:316.6 JEL M37

Щербакова Елена Валерьевна д-р культурологии, ГОУ ВО МО «Государственный социально-гуманитарный университет», г. Коломна, Российская Федерация

ORCID: 0000-0003-0754-9576

e-mail: cherval39@mail.ru

Белугина Диана Максимовна магистр, эксперт, ООО «Хендэ Мотор СНГ», г. Москва, Российская Федерация ORCID: 0000-0001-5375-3602 e-mail: dianabelugina@mail.ru

Звонова Елена Владимировна канд. пед. наук, ФГБОУ ВО «Московский педагогический государственный университет», г. Москва, Российская Федерация

ORCID: 0000-0001-9271-8367

e-mail: zevreturn@yandex.ru

\section{Shcherbakova Elena}

Doctor of Culturology, State University of Humanities and Social Studies, Kolomna, Russia

ORCID: 0000-0003-0754-9576

e-mail: cherval39@mail.ru

\section{Belugina Diana}

Master of degree, Expert, Hyundai

Motor CIS, Moscow, Russia

ORCID: 0000-0001-5375-3602

e-mail: dianabelugina@mail.ru

\section{Zvonova Elena}

Candidate of Pedagogical Sciences, Moscow Pedagogical State University, Moscow, Russia

ORCID: 0000-0001-9271-8367

e-mail: zevreturn@yandex.ru
DOI 10.26425/1816-4277-2020-8-200-206

\section{К ВОПРОСУ ОБ ЭФФЕКТИВНОСТИ НАРРАТИВНОЙ РЕКЛАМЫ В НАУЧНО-ПОПУЛЯРНЫХ ИЗДАНИЯХ}

Аннотация. Вопрос исследования эффективности рекламы в научно-популярных изданиях не занимает большого места в научных исследованиях. Данное положение дел является проблемным, поскольку деятельность научно-популярных изданий направлена на привлечение внимания и интереса молодежи, творческого и активного потенциала, к вопросам науки. В статье исследована эффективность нарративной рекламы как социально-психологической коммуникативной технологии. Исследование выполнено в рамках семиотического подхода. Описаны результаты исследования текстов нарративной рекламы, в котором приняли участие молодые люди, занимающиеся научной деятельностью, и молодые люди, чей профессиональный функционал не связан с научными исследованиями. Использованный инструментарий позволил выявить различия между восприятием текстов нарративной рекламы двумя группами респондентов, а также сходные тенденции восприятия текстов, что позволяет предположить о возможности разрабатывать эффективную рекламную стратегию продвижения научно-популярного журнала. Результаты исследования могут представлять интерес для специалистов, работающих в области рекламы, особенно в области рекламы интеллектуальных услуг.

Ключевые слова: медиатекст, нарратив, нарративная реклама, семиотический подход, специффика восприятия, структура, функиии, эффективность рекламыл.

Цитирование: Щербакова Е.В., Белугина Д.М., Звонова Е.В. К вопросу об эффективности нарративной рекламы в научно-популярных изданиях//Вестник университета. 2020. № 8. С. 200-206.

\section{ON THE ISSUE ABOUT THE EFFECTIVENESS OF NARRATIVE ADVERTISING IN POPULAR SCIENCE JOURNALS}

Abstract. The issue of studying the effectiveness of advertising in popular science journals does not occupy a large place in scientific research. This state of affairs is challenging, since the activities of popular science journals are aimed at attracting the attention and interest of young people, creative and active potential, to science issues. The effectiveness of narrative advertising as a social-psychological communication technology has been examined in the article. The research has been carried out within the framework of a semiotic approach. The results of the research of narrative advertising texts, in which young people engaged in scientific activities and young people whose professional functionality is not related to scientific research took part, have been described. The toolkit used made it possible to identify differences between the perception of narrative advertising texts by two groups of respondents and also similar trends in the perception of texts, which suggests a possibility of developing an effective advertising strategy for promoting a popular science magazine. The research results may be of interest for professionals working in the field of advertising, especially in the field of advertising of intellectual services.

Keywords: advertising efficiency, functions, media text, narrative, narrative advertising, semiotic approach, specificity of perception, structure.

For citation: Shcherbakova E.V., Belugina D.M., Zvonova E.V. (2020) On the issue about the effectiveness of narrative advertising in popular science journals. Vestnik universiteta. I. 8, pp. 200-206. DOI: $10.26425 / 1816-4277-2020-8-200-206$

Реклама, как явление современной жизни, занимает прочное место в картине окружающего мира. Она реализует важнейшую функцию экономической коммуникации, однако, трудно переоценить роль воздействия рекламного воздействия на сознание человека. Транслируя легко узнаваемые образы, реклама формирует

(C) Щербакова Е.В., Белугина Д.М., Звонова Е.В., 2020. Статья доступна по лицензии Creative Commons «Attribution» («Aтрибуция») 4.0. всемирная (http://creativecommons.org/licenses/by/4.0/).

The Author(s), 2020. This is an open access article under the CC BY 4.0 license (http://creativecommons.org/licenses/by/4.0/).

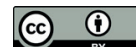


и закрепляет в общественном сознании стереотипы как символьное воплощение идеального, социально одобряемого поведения. Поэтому вопросы исследования социально-психологических условий, определяющих эффективность рекламных текстов, занимают внушительное место в теоретических обобщениях и практико-ориентированных исследованиях $[6 ; 7 ; 13]$.

Нарратив (от лат. narrare - язык повествования), как психологический прием моделирования воздействия рекламы на человека, представляет особый интерес, поскольку нарратив выступает как «феномен, появившийся в результате необходимости представлять свою внутреннюю сущность социальному окружению и участвовать в жизни других, делясь индивидуально постигнутыми ценностями и смыслами через диалог» $[16$, с. 83]. Изучение рекламы, важной части социальной коммуникации, как опосредствованной, символьной формы внутреннего состояния человека относится к перспективным направлениям развития современной психологической науки [11].

Нарративная реклама обычно представлена как история, рассказанная от имени участника ситуации, социального взаимодействия. Рассказ строится таким образом, чтобы респондент, воспринимающий данный текст, не просто обратил внимание, но ощутил свою вовлеченность, почти осязаемую сопричастность излагаемой последовательности событий. Нарративная реклама прибегает к разнообразным средствам лингвистического и визуального воздействия, стараясь вовлечь респондента в диалог, сделать его «значимым другим», мнение которого разделяется и учитывается автором.

Зародившись в историографии, термин «нарратив» стал использоваться для обозначения сугубо личностного пересказа некой информации, позволяющего осознавать и творить личностные смыслы, тем самым не только познавая себя, но и включаясь в активный дискурс с социальным окружением [2]. Исследование нарратива сосредоточено на процессах создания текстов, «посредством которых люди описывают, интерпретируют, делают для себя понятными самих себя и мир, в котором они живут» [15, с. 10]. Нарратив дискурсивен по своей сути, поскольку репрезентирует реконструкцию личностного опыта для себя самого и для других [23].

Нарратив - повествование, строящееся по определенным правилам речевого или художественного сообщения, касающегося системы субъектов и уровней повествования, отношений к адресату и предмету сообщения, типа повествовательного времени [1]. В развитии нарратологии, как литературоведческой дисциплины, базовую роль сыграл В. Я. Пропп, применивший структурно-семиотический подход к анализу волшебной сказки и выделивший 31 функцию персонажей, последовательность которых образует инвариантную структуру различных сюжетов [12]. Следуя за В. Я. Проппом, избравшим функцию в качестве элементарной единицы нарративного повествования, К. Леви-Стросс в середине XX в. выстроил концепцию структурной антропологии, а литературовед К. Бремон в работах 1960-1970-х гг. (на русский язык переведена «Логика структурного повествования») анализировал поля возможных нарративов. В это же время лингвист и семантик А. Ж. Греймас синтезировал синтагматический подход В. Я. Проппа и парадигматический подход К. Леви-Стросса с использованием достижений семантики, определив 20 парных функций и предложив идею порождающего нарративы семиотического квадрата. Нарративная (повествовательная) форма культуры, предполагающая общение людей в разных отношениях и контекстах, обсуждается в созданных с конца 1970-х гг. работах французского теоретика постмодернизма Ж.-Ф. Лиотара [9].

В работе «Состояние постмодерна» и в письмах 1980-х гг. («Постмодернизм в изложении для детей») Ж.-Ф. Лиотар называет особенностью культурной ситуации второй половины XX в. «закат больших нарративов» (рассказов) западной культуры. Подобные метанаррации, основанные на просветительском комплексе мировоззренческих идей (рационализме, сциентизме, антропоцентризме), упорядочивали общество и человеческое сознание. Но в постмодернизме технологический подъем на фоне памяти о трагических событиях второй мировой войны приводит к утрате доверия к метанарративам при сохранении значения «малых рассказов», закрепляющих целостность повседневной жизни.

Обосновывая основные положения нарративной психологии, Дж. Брунер утверждал, что в сознании человека функционирует определенный, социально генерируемый набор нарративных схем [19]. Мысль о том, что люди создают и воспроизводят формы социального поведения в стандартных социальных ситуациях, подтолкнула К. Бёрк операционализировать модель социального поведения в составе пяти основных элементов: действующее лицо, действие, обстановка, средства, цель. Стремясь определить мотивационный импульс, Дж. Брунер включает в модель социального поведения дополнительный элемент - трудность или препятствие. 
Нарратив в рекламе включает респондента в создаваемую ситуацию, которая позволяет человеку реализовать свои социальные функции, а сам текст представить как целостную неизменную структуру торжества желаемого результата над всеми помехами или трудностями, с обязательным благополучным исходом. Совершенно не важно, что в рекламе могут использоваться заведомо «сказочные» обещания типа «с нашим пылесосом весь мир в ваших руках». Нарратив отвечает одной из самых важных функций работы человеческого сознания - упорядочивание мира, в котором существует человек [18; 21].

Эффективная нарративная реклама обычно имеет некоторый «открытый конец», который позволяет каждому человеку ощутить свой интерес к рекламируемому товару или услуге как проявление своей общности с другими членами социума, размышляющими и пытающимися решить сходные проблемы, что и конкретная личность. В этом случае рекламируемый объект выступает как уникальное средство, «способ жить», прецедентный не только для одного, но типичный для конкретной культуры или даже общечеловеческий, мировой опыт взаимодействия с окружающей действительностью.

Нарратив помогает превратить восприятие рекламы в процесс личностного создания сообщения о себе для другого человека. Рекламное обращение строится по принципу «открытого текста», позволяет додумывать, мысленно менять контекст, «примерять», использовать для самого себя иные роли. Нарратив открывает возможность человеку создать приемлемый, эмоционально принимаемый мир и через описание собственного поведения, своей реакции на ситуацию, изменить себя. В этом великая самореализующая сила нарратива [20]. Осознание того, что ты не скован одним образом, но внутренний мир допускает существование и проявление многочисленных «Я-других» есть источник потенциального индивидуального саморазвития человека.

Таким образом, использование нарратива при создании рекламного текста нацелено на актуализацию двух коммуникативных процессов: монолога как способа познания себя и диалога как формы социального дискурса [8]. В ситуации монолога психологический механизм нарратива фокусируется на актуализации собственного «Я» в процессе включения в повествование, которое позволяет описать и оценить собственный опыт, потенциальные возможности и ресурсы. Диалог позволяет моделировать возможную реакцию других отдельных людей или групп, что помогает развить и укрепить собственную аргументацию коммуникативного посыла, в котором «рассказанное Я» помогает активно включиться в предлагаемый рекламным сообщением культурный контекст.

Нарративная реклама в первую очередь ориентирована на эмоциональный отклик и субъективную интерпретацию рекламного текста, субъективный пересказ значимых факторов, реализацию оценочного мифа как источника переживания [10].

Любая реклама должна быть понятной и читаемой, поэтому в процессе создания нарративной рекламы возможно использование ситуационных моделей, которые выступают в качестве «интегрированных структур предшествующего опыта» и являются хранилищем «для более общих и абстрактных «фреймов» или «сценариев» в семантической памяти. Они генерируют индивидуальные атрибутивные установки и представления, согласующиеся с определенными социальными ситуациями [5].

Существуют правила построения нарратива, которые рассматривают наличие основных базовых компонентов, расположенных по нисходящей линии:

- история рассказывается как исходная ситуация и эпизод, представленный в данном рекламном сообщении;

- эпизод раскрывается через попытку действовать, изменить исходную ситуацию;

- попытка действовать включает в себя план, собственно действие-преодоление и результат [2; 22].

Необходимо обратить внимание на то, что рекламные тексты, как правило, не являются исключительно словесными текстами, а составляют синкретическое коммуникативное послание, состоящее из слов и изображений, причем каждый элемент может выступать в роли знака или символа. При семиотическом анализе нарратива в медиатекстах реализуется проецирование содержания коммуникативного послания на систему средств, позволивших осуществить опосредствование. Семиотическая традиция рассматривает любой текст (в том числе и сократический, каким по своей сути чаще всего бывает реклама) как пространство, организованное и структурированное особым образом. Анализ каждого структурного элемента рекламного текста (слова, словосочетания, приема оформления, изображения, фотографии и т. п.) проводится в соответствии с функциональным признаком данного элемента через выделение той роли, которую он выполняет [3]. 
При реализации семиотического подхода системы знаков, используемые при создании объекта (в данном случае рекламного текста), рассматриваются как особый код, элементы которого предполагают при декодировании взаимное соотнесение. При этом необходимо выделять и анализировать две обязательные части: поверхностную структуру текста на уровне синтаксиса и слов и глубинную структуру, содержащую фундаментальную систему ценностей, норм и установок определенных социальных систем [14].

Семиотический анализ нарративной рекламы фокусируется на психологическом содержании используемых средств коммуникации, ориентированных на активизацию когнитивных процессов и схем, которые запускают «работу понимания» ситуации и помогают принять решение о возможных вариантах поведения. В результате происходит конструирование содержания рекламного сообщения как истории отдельного события, эксплицитно или имплицитно изображающего повествующую инстанцию.

Анализ современной практики показывает, что в рекламном тексте нарратив может быть использован в различных жанрах: житейской истории, отзыве, репортаже, экспертном отзыве, истории бренда, комиксе и др.

Наименее изученным видом рекламы является реклама в научно-популярных периодических изданиях. Как показывают наши исследования, в настоящее время функция научно-популярных изданий существенно изменилась. К ним обращается в данное время довольно много людей, особенно молодежи, однако, информация рассматривается не как информационно-содержательный контекст, а скорее как информационно-справочный: получая информацию в научно-популярном издании, большинство людей склонны ее рассматривать как некий предикт, предварительный этап, позволяющий координировать направление дальнейшего поиска. Поэтому роль научно-популярных изданий в современной социальной коммуникации трудно переоценить. Еще одна немаловажная функция научно-популярных изданий - обеспечение молодых людей платформой для публикации своих научных исследований, возможность найти единомышленников и ознакомиться с популярными направлениями современных научных изысканий.

Для проведения исследования нами были выбраны несколько рекламных объявлений журнала «Scientific Light», посвященных информированию о предстоящих научных мероприятиях и приглашению принять в них участие (опубликовать статью, стать участником конференции и пр.). Данные объявления привлекли наше внимание, поскольку они все были составлены с применением техники нарративной рекламы [22].

Эмпирическое исследование было проведено в 2018-2019 гг. в городе Москве. В исследовании приняли участие 41 человек в возрасте 25-35 лет. При этом 14 респондентов являются магистрантами, аспирантами или научными сотрудниками, эти группы мы назвали «специалисты». 27 человек научной деятельностью не занимаются.

Для исследования социально-психологической эффективности нарратива в текстах научного журнала «Scientific Light» была использована методика анализа эффективности рекламного текста М. А. Измайловой [4]. Данная методика направлена на измерение эффективности рекламы, которая, по мнению автора, проявляется в эмоциональном, когнитивном и поведенческом аспектах:

- переживаемые чувства и эмоции респондента при восприятии рекламного текста диагностируются как эмоциональный компонент рекламного воздействия;

- ясность восприятия и уровень запоминания содержания рекламы трактуется как когнитивный компонент;

- поведенческий компонент диагностируется по ответу респондента, совершит ли он целевое действие: купит продукт, воспользуется услугой.

Для проведения исследования оценки социально-психологической эффективности нарратива в текстах научно-популярного издания были использованы рекламные тексты журнала «Scientific Light», созданные с использованием приемов нарративной рекламы. Основной задачей коллектива журнала является привлечение молодежи к научно-исследовательской деятельности [17].

В результате проведенного эмпирического исследования были получены следующие результаты.

Необходимо отметить, что использование нарратива «замаскировало» назначение анализируемых текстов: почти половина респондентов не определили представленные им тексты как рекламные. Это можно объяснить тем, что у респондентов сформирован определенный стереотип рекламы: навязчивая, агрессивная и раздражающая.

Большая часть участников исследования отмечала, что их внимание привлекло именно содержание, а не визуальные элементы. Вместе с тем эмоциональная оценка текста, как понравившегося наибольшему числу респондентов, по результатам диагностики не соответствовала оценке качества как «высокого». 
При обосновании желания приобрести услугу (опубликоваться в журнале) респонденты отмечают следующие характеристики текста, оказавшие влияние на их выбор: положительная эмоциональная реакция после прочтения текста, а также доказательность аргументации в тексте. Данные характеристики отметили $36,6 \%$ и $31,7 \%$ респондентов соответственно.

Оценка эффективности восприятия нарратива в текстах научного журнала «Scientific Light» респондентами-специалистами и респондентами, не связанными с научной деятельностью, проводилась при помощи t-критерия Стьюдента $\left(\mathrm{t}_{\text {эмп }}=5,3, \mathrm{t}_{\mathrm{kp}}=2,042\right)$. Статистический анализ показал, что наблюдаемые различия эмоционального восприятия нарратива в одних и тех же текстах научного журнала «Scientific Light» pecпондентами-специалистами и респондентами, не связанными с научной деятельностью, статистически значимы (уровень значимости $\mathrm{p}<0,05$ ).

Оценки значимости различий запоминаемости текстов рекламы, использующих нарратив, с применением t-критерия Стьюдента показали, что наблюдаемые различия запоминаемости респондентами-специалистами и респондентами, не связанными с научной деятельностью, статистически значимы $\left(\mathrm{t}_{\text {эмп }}=4,4\right.$, $\mathrm{t}_{\mathrm{\kappa p}}=2,042$, уровень значимости $\left.\mathrm{p}<0,05\right)$.

Однако, статистический анализ показал, что различия восприятия убедительности аргументации в текстах научного журнала «Scientific Light» респондентами-специалистами и респондентами, не связанными с научной деятельностью, статистически не значимы (уровень значимости $\mathrm{p}<0,05$ ).

Различия социально-психологической эффективности восприятия нарратива в текстах научного журнала «Scientific Light» респондентами-специалистами и респондентами, не связанными с научной деятельностью, статистически значимы $\left(\mathrm{t}_{\text {эмп }}=2,245, \mathrm{t}_{\mathrm{kp}}=2,021\right.$, уровень значимости $\left.\mathrm{p}<0,05\right)$. Респонденты, связанные с научной деятельностью, меньше высказали желания опубликоваться в журнале, чем респонденты, не связанные с научной деятельностью.

Интервью с участниками исследования подтвердило полученные результаты: внимание участников исследования привлекла подача текста с применением техники нарратива, позволяющей почувствовать себя участником описываемого мероприятия. Высокой социально-психологической эффективностью обладают такие характеристики текстов, как убедительная аргументация и предоставление дополнительной информации о журнале. Однако наибольшей эффективностью обладает эмоциональное воздействие текстов.

Тексты рекламы в научно-популярном издании по-разному воспринимаются респондентами-специалистами и респондентами, не связанными с научной деятельностью. Респонденты-специалисты больше внимания уделяют таким характеристикам, как запоминаемость, эмоциональное отношение, восприятие содержания и визуального оформления. В свою очередь, респонденты, не связанные с научной деятельностью, демонстрируют более низкий уровень доверия к информации в текстах.

\section{Библиографический список}

1. Доброхотов, А. Л. Телеология культуры. - М.: Прогресс-Традиция, 2016. -528 с.

2. Елфимова, М. М. Нарратив как инструментальное средство произвольного смыслообразования // Вопросы психологии. - 2018. - № 1. - С. 90-103.

3. Звонова, Е. В. Символизация и метакогнитивное опосредование: продолжение культурно-исторической традиции // Вестник российского нового университета. - 2014. - № 1. - С. 34-36.

4. Измайлова, М. А. Психология рекламной деятельности. - М.: Дашков и Ко, 2011. - 444 с.

5. Казанцева, Е. В., Липовая, О. А. К вопросу о характеристике нарративной структуры социальных представлений // Психология и психотехника. - 2019. - № 1. - С. 33-43. doi: 10.7256/2454-0722.2019.1.29275

6. Комарова, А. А., Новиков, В. Г., Захаров, М. Ю. Роль социологических исследований в планировании рекламных кампаний // Вестник университета. - 2019. - № 2. - С. 145-149. doi: 10.26425/1816-4277-2019-2-145-149.

7. Лебедев, А. Н. Психологическая, экономическая и социальная эффективность рекламы в современных маркетинговых коммуникациях // Психологический журнал. - 2015. - № 36 (2). - С. 5-19.

8. Леонтьев, А. Н. Прикладная психолингвистика речевого общения и массовой коммуникации. - М.: НПФ Смысл, 2011. -272 с.

9. Лиотар, Ж.-Ф. Состояние постмодерна. - СПб.: Алетейя, 2013. - 159 с.

10. Марцинковская, Т. Д., Турушева, Ю. Б. Нарратив как методология исследования личности в ситуации транзитивности // Психологические исследования. - 2017. - № 10 (52) [Электронный ресурс]. - Режим доступа: http://psystudy.ru/index. php/num/2017v10n52/1401-martsinkovskaya52.html (дата обращения: 16.07.2020). 
11. Панферов, В. Н., Журавлев, А. Л., Дробышева, Т. В. Интегративный подход в социальной психологии как развитие методологии комплексного человекознания (интервью с В. Н. Панферовым) // Институт психологии Российской академии наук. Социальная и экономическая психология. - 2018. - Т. 3. - № 1 (9). - С. 123-147.

12. Пропп, В. Морфология волшебной сказки. - М.: Лабиринт, 2008. - 384 с.

13. Соклакова, И. В., Сурат, И. Л. Особенности рекламы в сфере электронной коммерции // Вестник университета. - 2018. № 5. - С. 120-125. doi: 10.26425/1816-4277-2018-5-120-125.

14. Тичер, С., Мейер, М., Водак, Р., Веттер, Е. Методы анализа текста и дискурса. - М.: Гуманитарный центр, 2009. - 356 с.

15. Турушева, Ю. Б. Нарративный подход к проблеме развития смысловых образований: автореф. дисс. ... канд. психол. наук: 19.00.01 / Психологический институт РАО. - Москва, 2017. - 22 с.

16. Хайдеггер, М. Бытие и время. - М.: Академический проект, 2015. - 460 с.

17. Официальный сайт журнала «Scientific Light» [Электронный ресурс]. - Режим доступа: https://www.slg-journal.com/ main (дата обращения: 16.07.2020).

18. Bamberg, M., Demuth, C. Narrative inquiry: an interview with Michael Bamberg // Europe's Journal of Psychology. - 2016. Vol. 12. - No. 1. - Pp. 14-28. doi: 10.5964/ejop.v12i1.1128.

19. Bruner, J. Making stories: law, literature, life. - Harvard University Press, 2003. - 144 p.

20. Burton, R. Personal narrative of a pilgrimage to Al-Madinah and Meccah (Volume 1). Paperback. - NY: Dover Publications; Revised ed. edition (June 1, 1964), 1986. - 480 p.

21. Labov, W. The language of life and death: the transformation of experience in oral narrative. - Cambridge University Press, 2013. -234 p. doi: 10.1111 josl.12122.

22. Pleh, Cs. Narrativity in text construction and self-construction // Neohelicon. - 2003. - No. 1. - Pp. 187-205. doi: 10.1023/A:1024178827479.

23. Schiffrin, D. In other words: variation in reference and narrative. - Cambridge, 2006. -390 p.

\section{References}

1. Dobrokhotov A. L. Teleologiya kul'tury [Teleology of culture]. Moscow, Progress-Traditsiya, 2016. 528 p.

2. Elfimova M. M. Narrativ kak instrumental'noe sredstvo proizvol'nogo smysloobrazovaniya [The narrative as an instrument for arbitrary sense formation]. Voprosy psikhologii [Voprosy Psychologii], 2018, no. 1, pp. 90-103.

3. Zvonova E. V. Simvolizatsiya i metakognitivnoe oposredovanie: prodolzhenie kul'turno-istoricheskoi traditsii [Symbolization and metacognitive mediation: sequel of cultural and historical tradition]. Vestnik rossiiskogo novogo universiteta [Vestnik of Russian New University (Vestnik RosNOU)], 2014, no.1, pp. 34-36.

4. Izmailova M. A. Psikhologiya reklamnoi deyatel'nosti [Psychology of advertising activity]. Moscow, Dashkov i Ko., 2011. 444 p.

5. Kazantseva E. V., Lipovaya O. A. K voprosu o kharakteristike narrativnoi struktury sotsial'nykh predstavlenii [On the issue about the characterization of the narrative structure of social representations]. Psikhologiya i psikhotekhnika [Psychology and Psychotechnics], 2019, no. 1, pp. 33-43. doi: 10.7256/2454-0722.2019.1.29275.

6. Komarova A. A., Novikov V. G., Zakharov M. Yu. Rol' sotsiologicheskikh issledovanii v planirovanii reklamnykh kampanii [The role of sociological research in the planning of advertising campaigns]. Vestnik Universiteta, 2019, no. 2, pp. 145-149. doi: 10.26425/1816-4277-2019-2-145-149.

7. Lebedev A. N. Psikhologicheskaya, ekonomicheskaya i sotsial'naya effektivnost' reklamy v sovremennykh marketingovykh kommunikatsiyakh [Psychological, economic and social efficiency of advertising in modern marketing communications]. Psikhologicheskii zhurnal [Psychological Journal], 2015, no. 36 (2), pp. 5-19.

8. Leont'ev A. N. Prikladnaya psikholingvistika rechevogo obshcheniya i massovoi kommunikatsii [Applied psycholinguistics of verbal communication and mass communication]. Moscow, NPF Smysl, 2011. $272 \mathrm{p}$.

9. Lyotard J.-F. Sostoyanie postmoderna [The condition of postmodernity]. St. Petersburg, Aleteiya, 2013. 159 p.

10. Martsinkovskaya T. D., Turusheva Yu. B. Narrativ kak metodologiya issledovaniya lichnosti v situatsii tranzitivnosti [Narrative as methodology, investigating the personality in the situation of the transitivity]. Psikhologicheskie issledovaniya, 2017, no. 10 (52). Available at: http://psystudy.ru/index.php/num/2017v10n52/1401-martsinkovskaya52.html (accessed 16.07.2020).

11. Panferov V. N., Zhuravlev A. L., Drobysheva T. V. Integrativnyi podkhod v sotsial'noi psikhologii kak razvitie metodologii kompleksnogo chelovekoznaniya (interv'yu s V. N. Panferovym) [Integrative Approach in Social Psychology as Development of Methodology of Complex Human Knowledges (Interview with V. N. Panferov)]. Institut psikhologii Rossiiskoi akademii nauk. Sotsial'naya i ekonomicheskaya psikhologiya, 2018, vol. 3, no. 1 (9), pp. 123-147. 
12. Propp V. Morfologiya volshebnoi skazki [Morphology of magic fairy tale]. Moscow, Labirint, 2008. 384 p.

13. Soklakova I. V., Surat I. L. Osobennosti reklamy v sfere elektronnoi kommertsii [Peculiarities of advertising in e-commerce]. Vestnik Universiteta, 2018, vol. 5, pp. 120-125. doi: 10.26425/1816-4277-2018-5-120-125.

14. Titscher S., Meyer M., Wodak R., Vetter E. Metody analiza teksta i diskursa [Methods of text and discourse analysis]. Moscow, Gumanitarnyi tsentr, 2009. 356 p.

15. Turusheva Yu. B. Narrativnyi podkhod k probleme razvitiya smyslovykh obrazovanii [Narrative approach to the problem of development of semantic formations]: avtoref. dis. kand. psikhol. nauk: 19.00.01. Psikhologicheskii Institut RAO. Moscow, 2017. 22 p.

16. Heidegger M. Bytie i vremya [Being and time]. Moscow, Akademicheskii proekt, 2015. 460 p.

17. Ofitsialnyi sait zhurnala [Official website of the magazine "Scientific Light"]. Available at: https://www.slg-journal.com/main (accessed 16.07.2020).

18. Bamberg M., Demuth C. Narrative inquiry: an interview with Michael Bamberg. Europe's Journal of Psychology, 2016, vol. 12, no. 1, pp.14-28. doi: 10.5964/ejop.v12i1.1128.

19. Bruner J. Making stories: law, literature, life. Harvard University Press, 2003. 144 p.

20. Burton R. Personal narrative of a pilgrimage to Al-Madinah and Meccah (Volume 1). Paperback. NY, Dover Publications; Revised ed. edition (June 1, 1964), 1986. 480 p.

21. Labov W. The language of life and death: the transformation of experience in oral narrative. Cambridge University Press, 2013. 234 p. doi: $10.1111 /$ josl.12122.

22. Pleh Cs. Narrativity in text construction and self-construction. Neohelicon, 2003, no. 1, pp. 187-205. doi: 10.1023/A:1024178827479.

23. Schiffrin D. In other words: variation in reference and narrative. Cambridge, 2006. 390 p. 